\title{
Do you Teach Leadership?
}

\author{
Libby V. Morris ${ }^{1}$
}

Published online: 26 March 2018

(C) Springer Science+Business Media, LLC, part of Springer Nature 2018

Do you teach leadership? It occurred to me that most of my university colleagues would reply "no" if asked this question. The explanation would be that corporate leadership is taught in business schools, and non-profit leadership in public administration programs, and school leadership in education, and so on. It would be noted that many stand-alone leadership courses and non-credit programs are offered through both academic and student affairs. It is understandable that most faculty members would reply "no".

Adding to the complexity of the question is the extensive literature on leadership with works dating to the time of Plato and Socrates. Stories and examples of managing tasks, motivating people, and engaging in leadership are told in literature across cultures and across centuries. Thus, it is not surprising that my recent search yielded almost 200,000 peerreviewed journal articles with leadership in the title. More than 30,000 books were returned with leadership and/or management in the title (2000-current).

The accumulated literature presents several theories of leadership: Great Man and trait theories, behavioral/style theories, transactional and transformative leadership, situational and contingency theories, and the emerging research into distributed leadership. Who has not heard of servant leadership, team leadership, and charismatic leadership? Using these theories, others unnamed, and combinations thereof, colleges and universities offer a wide range of leadership programs. A quick search of the University of Georgia (UGA) website yielded several, student-focused leadership programs. For example, UGA's Terry College of Business offers the Leonard Leadership Scholars program to approximately 30 students annually. See http://www.terry.uga.edu/academics/certificates/leonard-scholars. This certificate program for business undergraduates requires 3 three-credit hour courses, extracurricular activities, and a service learning project.

The UGA Student Affairs' Center for Leadership and Service coordinates Leadershape ${ }^{\circledR}$ $U G A$, which includes a six-day leadership development experience to introduce students to personal and group leadership. See https://cls.uga.edu/content_page/leadershape. As a selective program, it gives a small group of students a chance to interact with business and governmental leaders across the state.

Libby V. Morris

lvmorris@uga.edu 
The UGA heavyweight in statewide leadership is the J.W. Fanning Institute for Leadership Development, a unit of public service and outreach, which convenes groups and supports leadership and personal skill development on and off-campus. Recently, the Institute launched programs with faculty in academic units to embed leadership development into curricular programs. For example, the Emerging Engineering Leaders Development Program links engineering faculty and Fanning Institute faculty to offer leadership development in civil and environmental engineering. See https:/www.fanning.uga.edu/programs/emergingengineering-leaders-development-program/. This pilot program supports the capstone senior design course and puts Fanning Institute faculty in the classroom with engineering faculty at designated points throughout the year.

The examples above show commitment to leadership development for students and the steps taken to integrate leadership into academic programs. I must admit that I do not know the leadership theories that underpin these or other credit and non-credit programs on campus; but it is common to see communication, collaboration, and teamwork listed as key components. I would argue that faculty members are regularly exposing students to leadership opportunities in their courses and programs, whether these tasks are explicitly identified as leadership or not. We know active learning is characterized by student interaction, shared projects, peer-to-peer feedback, and teamwork. In classes we often establish teams or allow students to self-select into groups. Teamwork engages leaders and followers; it requires communication and collaboration. Alas, some students will complain about the team and will push to work independently, not unlike the workplace. Theories and tenets of leadership are played out all the time in our classrooms.

Needless to say, I am not suggesting that faculty members should become experts in leadership, nor am I arguing that we assign more responsibilities to already overworked instructors. Yet, based on contemporary pedagogies, it seems we may be effectively or ineffectively, consciously or unconsciously, "teaching leadership" in our courses and programs. While only a small percentage of students may be exposed to formal leadership programs, the large majority are likely forming ideas about leading and following based on participation in courses where teamwork is expected and where leadership roles are assigned, assumed, and perhaps unexamined.

Increasingly, business and nonprofit leaders report that college students must learn teamwork and must understand how to collaborate in diverse groups around complex, challenging problems for success in employment and other areas. We should recognize the important role that faculty play in leadership development in the classroom and give support to their attempts to understand and explain the association between group process and group outcomes. It is unlikely that UGA, with almost 29,000 undergraduates and approximately 9000 graduate students, will ever offer enough "specialty" leadership programs to touch every student. However, every student, in my opinion, needs exposure to what it means to be an effective leader and an effective follower in diverse teams trying to solve complex problems. The question is as follows. How can we effectively achieve this goal in the classroom, the place of contact for every student? I wonder what is happening on your campuses, in your classrooms. 